\title{
Predictors of Weight Loss in Obese Older Adults: Findings from the USA and the UK
}

\author{
Sarah E. Jackson Rebecca J. Beeken Jane Wardle \\ Department of Epidemiology and Public Health, University College London, London, UK
}

\section{Key Words}

Weight loss · Aging · Obesity · Prevalence $\cdot$ Predictors

\begin{abstract}
Objective: To examine the prevalence and demographic predictors of clinically meaningful weight loss in community samples of obese older adults in the USA and the UK. Methods: Data were from obese older adults (BMI $\geq 30 \mathrm{~kg} / \mathrm{m}^{2}$; age $\geq 52$ years), free of a cancer diagnosis, from the Health and Retirement Study (HRS; $n=3398$ ) and the English Longitudinal Study of Ageing (ELSA; $n=998$ ). Weight change was assessed from 2004 to 2008 . Multivariable logistic regression tested whether age, sex, ethnicity, marital status, education, or BMI predicted $\geq 5 \%$ weight loss. Results: Over a quarter (28.7\%) of obese participants from HRS and $16.6 \%$ from ELSA lost $\geq 5 \%$ weight. Being female (odds ratio $(O R)=1.31,95 \%$ confidence interval $(\mathrm{CI})=1.11-1.54)$ and heavier $\left(\mathrm{BMI} \geq 35 \mathrm{~kg} / \mathrm{m}^{2}\right)(\mathrm{OR}=1.60,95 \% \mathrm{CI}=1.37-1.87)$ predicted weight loss in HRS. Trends were similar in ELSA (female: OR $=1.18,95 \% \mathrm{CI}=0.83-1.69$; $\mathrm{BMI} \geq 35 \mathrm{~kg} / \mathrm{m}^{2}:$ OR $\left.=1.24,95 \% \mathrm{CI}=0.85-1.82\right)$. ORs were increased in $\geq 65$-year-olds in HRS $(\mathrm{OR}=1.55,95 \% \mathrm{CI}=1.33-1.81)$, and reduced in married people in ELSA (OR $=0.69,95 \% \mathrm{CI}=$ 0.48-1.00). Neither education nor ethnicity predicted weight loss in either cohort. Conclusion: A high proportion of obese older adults experience clinically meaningful weight loss, but few demographic variables consistently predict weight loss in this population.
\end{abstract}


Jackson et al.: Predictors of Weight Loss in Obese Older Adults: Findings from the USA and the UK

\section{Introduction}

Recent estimates indicate higher rates of obesity among older than younger adults [1,2]. Older age and obesity are independent risk factors for a variety of chronic health conditions, including arthritis, hypertension, diabetes, heart disease, and cancer [3, 4]. Obesity also has significant functional implications in older people; worsening the age-related decline in physical function, and leading to frailty, impaired quality of life, and increased likelihood of nursing home admission [5].

There has been some controversy over the optimal BMI at older ages [6], with some cohorts of elderly subjects indicating lower mortality and better outcome in several chronic diseases and health circumstances in obese individuals; known as the 'obesity paradox' $[7,8]$. However, a recent review concluded that 'modest weight loss among obese individuals, regardless of age, can produce significant health benefits and reduce societal burden' [9]. The review also encouraged health care providers to target obese older adults who could benefit from participating in weight loss interventions.

Losing just $5 \%$ of initial body weight confers significant improvements in cardiometabolic risk [10,11], and is widely used as an indicator of clinically meaningful weight loss [12]. Most obese adults say they want to lose weight (93\%), and the majority report actively trying to lose weight (63\%) [13]. Recent NHANES data indicated that $26 \%$ of obese adults had lost at least $5 \%$ of body weight within the previous year [14], but the reliance on recalled weights in this report means that weight loss may have been overestimated. Prospective data from cohort studies would give a better estimate of the rates of clinically meaningful weight loss. In the clinical trial context, fewer past weight loss attempts and higher BMI are consistent predictors of successful weight loss [15], but trial samples tend not to be representative of the general population [16-18] and rarely focus on older adults [19]. Relatively few studies have examined the predictors of clinically meaningful weight loss in population samples. In the NHANES analysis [14] effects were not examined by age group.

Given the controversy around the benefits of weight loss for obese elderly adults, a better understanding of the rates of significant weight loss and who is losing weight within the older adult population is important.

This study investigated the prevalence and demographic predictors of clinically meaningful ( $\geq 5 \%$ ) weight loss among obese participants in large epidemiological cohort studies of older adults from the USA and the UK. Although data on the intentionality of weight loss were not available for the US sample, we were able to explore differences in predictors for intentional and non-intentional weight loss within the UK sample.

\section{Subjects and Methods}

\section{Study Populations}

The data for these analyses are from obese participants in two cohort studies: the Health and Retirement Study (HRS) and the English Longitudinal Study of Ageing (ELSA). These are population-based cohorts of US and UK adults aged 50 or older that have a degree of harmonization in their data collection protocols. Further details on the cohorts and sampling methods have been published elsewhere [20,21]. Participants in both cohorts gave full informed consent for participation, and ethical approval was obtained from the relevant ethics committees.

Health and Retirement Study

The original HRS cohort was recruited in 1992 with interviews of a large sample of US adults born between 1931 and 1941, when they were aged 51-61 years, plus their spouses or partners, regardless of their age. Participants are re-interviewed every 2 years, with additional cohorts added to the survey every 
Jackson et al.: Predictors of Weight Loss in Obese Older Adults: Findings from the USA and the UK

three waves (6 years). Weight and height data are self-reported. Eleven waves of HRS data have been collected to date. For comparability with the timing of the ELSA data collection (below), waves 7 and 9 (2004 and 2008) were selected as the baseline and follow-up assessments for these analyses.

\section{English Longitudinal Study of Ageing}

ELSA is a panel study drawn from households with one or more members aged $\geq 50$ years responding to the Health Survey for England in 1998, 1999, and 2001. Participants are followed up every 2 years, with nurse visits to collect objective measures of health status in alternate waves. Data from waves 2 and 4 (collected 2004/2005 and 2008/2009) form the baseline and follow-up examinations for the analyses reported here.

\section{Measures}

Interviewers collected demographic information, including age, sex, ethnicity, marital status, and highest level of education. Age was categorized as $<65$ years vs. $\geq 65$ years, ethnicity as white vs. non-white, marital status as married (including living as married) vs. unmarried (single/never married, separated, divorced, or widowed), and education as lower (HRS: graduated high school or less; ELSA: no qualifications/ school-age qualifications) vs. higher (HRS: some college or more; ELSA: university degree or equivalent).

Anthropometric variables were self-reported in HRS and objectively measured in ELSA, and included height and weight at baseline and follow-up, from which BMI at each time point was calculated. For these analyses BMI was dichotomized into class I obesity $\left(<35 \mathrm{~kg} / \mathrm{m}^{2}\right)$ vs. class II/III obesity $\left(\geq 35 \mathrm{~kg} / \mathrm{m}^{2}\right)$.

Clinically meaningful weight loss was defined as loss of $\geq 5 \%$ of baseline body weight over the 4 -year follow-up period.

No data were available on intention to lose weight in HRS. However, in the 1998 Health Survey for England, from which around a third of the original ELSA sample was recruited, respondents were asked: 'At the present time are you trying to lose weight, trying to gain weight, or are you not trying to change your weight?' This was used as a crude measure of intention to lose weight for the purpose of this study.

\section{Statistical Analyses}

The primary analyses compared obese individuals who lost at least $5 \%$ of their initial body weight (clinically meaningful weight losers) with the rest of the obese group. Differences in demographic variables between groups were explored with one-way independent analyses of variance (ANOVAs) for continuous variables and chi-square analyses for categorical variables. Multivariable logistic regression was used to assess the independent contributions of age, sex, ethnicity, marital status, education, and BMI in predicting weight loss. Interactions between sex and each predictor were tested, but none was significant.

Analyses were repeated excluding any individuals who gained more than $5 \%$ of initial weight in case inclusion of weight gainers affected the results. The logistic regression model was also rerun in the ELSA cohort for all participants who had data available on intention to lose weight $(n=422,42.3 \%)$ stratifying by intentionality status. Intention data were dichotomized to distinguish between those who intended to lose weight (i.e., reported trying to lose weight) at wave 0 (the wave of the Health Survey for England from which the participant was recruited into ELSA) and those who did not (i.e., reported either trying to gain weight or not trying to change their weight).

All analyses were carried out using IBM SPSS Statistics version 19, with a two-sided $\mathrm{p}<0.05$ determining statistical significance.

\section{Results}

Obesity prevalence (BMI $\geq 30 \mathrm{~kg} / \mathrm{m}^{2}$ ) at baseline in the full samples was $27 \%(\mathrm{n}=$ $5,370 / 19,750)$ in HRS and 20\% $(n=1,462 / 7,160)$ in ELSA. The present analyses included all participants with a BMI $\geq 30 \mathrm{~kg} / \mathrm{m}^{2}$ at baseline for whom reliable weight data were also 
Jackson et al:: Predictors of Weight Loss in Obese Older Adults: Findings from the USA and the UK

Table 1. Characteristics of obese people in two older adult cohorts at baseline

\begin{tabular}{lll}
\hline Characteristics & HRS $(\mathrm{n}=3,398)$ & ELSA $(\mathrm{n}=998)$ \\
\hline Age & & \\
$\quad$ Mean (SD), years & $64.2(8.2)$ & $63.6(8.0)$ \\
$\quad<65$ years, No. $\%)$ & $1,839(54.1)$ & $585(58.6)$ \\
$\quad \geq 65$ years, No. (\%) & $1,559(45.9)$ & $413(41.4)$ \\
Sex, No. (\%) & & \\
$\quad$ Male & $1,383(40.7)$ & $417(41.8)$ \\
$\quad$ Female & $2,015(59.3)$ & $581(58.2)$ \\
Ethnicity, No. (\%) & & \\
$\quad$ White & $2,538(74.7)$ & $981(98.3)$ \\
$\quad$ Non-white & $860(25.3)$ & $17(1.7)$ \\
Marital status, No. (\%) & & \\
$\quad$ Unmarried & $1,175(34.6)$ & $283(28.4)$ \\
$\quad$ Married & $2,216(65.2)$ & $715(71.6)$ \\
Education, No. (\%) & & \\
$\quad$ Lower & $2,146(63.2)$ & $774(77.6)$ \\
$\quad$ Higher & $1,248(36.7)$ & $219(21.9)$ \\
Weight, mean (SD), kg & $97.9(16.9)$ & $91.1(12.7)$ \\
BMI & & \\
$\quad$ Mean (SD), kg/m ${ }^{2}$ & $34.5(4.6)$ & $33.6(3.9)$ \\
$\quad<35 \mathrm{~kg} / \mathrm{m}^{2}$, No. (\%) & $2,281(67.1)$ & $754(75.6)$ \\
$\quad \geq 35 \mathrm{~kg} / \mathrm{m}^{2}$, No. $(\%)$ & $1,117(32.9)$ & $244(24.4)$ \\
\hline
\end{tabular}

Note: Where No. (\%) is given, numbers may not sum to total sample number, as some items were not answered by all participants. Percentages were derived from the full sample and may therefore not sum to $100 \%$.

available at the next evaluation ( $\mathrm{n}=4,541 / 5,370$ in HRS, $\mathrm{n}=1,069 / 1,462$ in ELSA). In the HRS cohort, a lower age limit of 52 years at baseline was set to match the age range in ELSA; this excluded 463 individuals. Individuals reporting cancer at either wave were also excluded (HRS: $\mathrm{n}=680$; ELSA: $\mathrm{n}=71$ ) because of the known association with weight loss [22]; leaving sample sizes of 3,398 in HRS and 998 in ELSA.

Sample characteristics are displayed in table 1. The obese participants from the HRS and ELSA samples were closely matched on age and sex, but HRS included a higher proportion of non-white (25.3\% vs. $1.7 \%)$, unmarried ( $34.6 \%$ vs. $28.4 \%)$, and more educated participants (36.7\% vs. $21.9 \%$ ) than ELSA. In addition, HRS participants were heavier and had a higher BMI at baseline than ELSA participants (mean weight: 97.9 vs. $91.1 \mathrm{~kg}$; mean BMI: 34.5 vs. $33.6 \mathrm{~kg} / \mathrm{m}^{2}$ ), and more had class II/III obesity (32.9\% vs. $24.4 \%$ ).

Prevalence of losing at least $5 \%$ of body weight was $28.7 \%$ in HRS (mean weight loss 12.1 $\mathrm{kg} ; 12.1 \%$ of initial body weight) and $16.6 \%$ in ELSA (mean weight loss $8.0 \mathrm{~kg} ; 8.9 \%$ of initial body weight). Descriptive data comparing those who did with those who did not lose at least $5 \%$ body weight are shown in table 2 . In the HRS cohort, weight losers were significantly more likely to be $\geq 65$ years old ( $53.1 \%$ vs. $43.0 \%$ ), female ( $64.6 \%$ vs. $57.0 \%$ ), and to have class II/ III obesity ( $40.4 \%$ vs. $29.8 \%$ ). There were nonsignificant trends in the same direction in ELSA (age $\geq 65$ years: $45.2 \%$ vs. $40.6 \%$; female: $63.3 \%$ vs. $57.2 \%$; class II/III obesity: $28.3 \%$ vs. $23.7 \%$ ). In both samples, weight losers were significantly less likely to be married than those who did not lose weight (61.8\% vs. $66.6 \%$ in HRS; $63.9 \%$ vs. $73.2 \%$ in ELSA). In HRS, weight losers were also significantly less likely to be highly educated (33.7\% vs. 37.9\%), and the same pattern, but not significant, was seen in ELSA (20.5\% vs. 22.2\%). There were no signif- 
Jackson et al.: Predictors of Weight Loss in Obese Older Adults: Findings from the USA and the UK

Table 2. Characteristics of weight losers $(\geq 5 \%)$ among obese people in two older adult cohorts

\begin{tabular}{|c|c|c|c|c|c|c|}
\hline \multirow[t]{2}{*}{ Characteristics } & \multicolumn{3}{|c|}{ HRS cohort $(n=3,398)$} & \multicolumn{3}{|c|}{ ELSA cohort $(n=998)$} \\
\hline & $\begin{array}{l}\text { no weight loss } \\
(n=2,423,71.3 \%)\end{array}$ & $\begin{array}{l}\geq 5 \% \text { weight loss } \\
(n=975,28.7 \%)\end{array}$ & $\begin{array}{l}\chi^{2} \\
\mathrm{p}\end{array}$ & $\begin{array}{l}\text { no weight loss } \\
(\mathrm{n}=832,83.4 \%)\end{array}$ & $\begin{array}{l}\geq 5 \% \text { weight loss } \\
(\mathrm{n}=166,16.6 \%)\end{array}$ & $\begin{array}{l}\chi^{2} \\
\mathrm{p}\end{array}$ \\
\hline \multicolumn{7}{|l|}{ Age, No. (\%) } \\
\hline$<65$ years & $1,382(57.0)$ & $457(46.9)$ & $<0.001$ & $494(59.4)$ & $91(54.8)$ & 0.227 \\
\hline$\geq 65$ years & $1,041(43.0)$ & $518(53.1)$ & - & $338(40.6)$ & $75(45.2)$ & - \\
\hline \multicolumn{7}{|l|}{ Sex, No. (\%) } \\
\hline Male & $1,041(43.0)$ & $342(35.1)$ & $<0.001$ & $356(42.8)$ & 61 (36.7) & 0.150 \\
\hline Female & $1,382(57.0)$ & $633(64.6)$ & - & $476(57.2)$ & $105(63.3)$ & - \\
\hline \multicolumn{7}{|c|}{ Ethnicity, No. (\%) } \\
\hline White & $1,828(75.4)$ & 710 (72.8) & 0.112 & $818(98.3)$ & $163(98.2)$ & 0.910 \\
\hline Non-white & $595(24.6)$ & $265(27.2)$ & - & $14(1.7)$ & $3(1.8)$ & - \\
\hline \multicolumn{7}{|c|}{ Marital status, No. (\%) } \\
\hline Unmarried & 807 (33.3) & 368 (37.7) & 0.012 & $223(26.8)$ & $60(36.1)$ & 0.015 \\
\hline Married & $1,613(66.6)$ & $603(61.8)$ & - & $609(73.2)$ & $106(63.9)$ & - \\
\hline \multicolumn{7}{|c|}{ Education, No. (\%) } \\
\hline Lower & $1,501(61.9)$ & $645(66.2)$ & 0.022 & $643(77.3)$ & 131 (78.9) & 0.623 \\
\hline Higher & $919(37.9)$ & 329 (33.7) & - & $185(22.2)$ & $34(20.5)$ & - \\
\hline \multicolumn{7}{|l|}{ BMI, No. (\%) } \\
\hline$<35 \mathrm{~kg} / \mathrm{m}^{2}$ & $1,700(70.2)$ & 581 (59.6) & $<0.001$ & 635 (76.3) & 119 (71.7) & 0.205 \\
\hline$\geq 35 \mathrm{~kg} / \mathrm{m}^{2}$ & $723(29.8)$ & $394(40.4)$ & - & $197(23.7)$ & 47 (28.3) & - \\
\hline
\end{tabular}

Note: Numbers may not sum to total sample number, as some items were not answered by all participants. Percentages were derived from the full sample and may therefore not sum to $100 \%$.

icant differences by ethnicity in either sample, perhaps due to the small number of non-white participants, particularly in the ELSA cohort.

Prevalence of weight loss by demographic characteristics and level of obesity is shown in table 3. Comparing the two cohorts, weight loss prevalence was higher in HRS than in ELSA in every subgroup. However, prevalence was more similar in younger (24.9\% in HRS vs. $15.6 \%$ in ELSA) than older adults (33.2\% in HRS vs. $18.2 \%$ in ELSA), and in those with class I obesity (25.5\% in HRS vs. 15.8\% in ELSA) than the class II/III obese (35.3\% in HRS vs. 19.3\% in ELSA).

In the multivariable logistic regression models (table 3), being female and having a higher BMI significantly predicted weight loss in the HRS sample, and there were nonsignificant trends in the same direction in ELSA. Older age was associated with weight loss in HRS, but no effect was seen in ELSA. There was a significant effect of marital status in ELSA, with married participants being less likely to lose weight than unmarried participants, but not in HRS. Neither education nor ethnicity predicted weight loss in either sample.

We repeated the analyses excluding individuals who gained weight (HRS $n=692$; ELSA $\mathrm{n}=152$ ) from the comparison group to ensure that observed differences were not due to the characteristics of weight gainers. This did not significantly alter the pattern of results. The odds ratios (ORs) of weight loss in obese women were slightly higher (HRS: OR $=1.40,95 \%$ confidence interval $(\mathrm{CI})=1.18-1.66, \mathrm{p}<0.001$; ELSA: OR $=1.24,95 \% \mathrm{CI}=0.86-1.78, \mathrm{p}=$ 0.243 ), and the OR of weight loss in older participants in HRS was slightly lower (OR $=1.32$, $95 \% \mathrm{CI}=1.13-1.56, \mathrm{p}=0.001$ ).

We also repeated the analyses in the ELSA cohort for all participants who had data available on intention to lose weight $(n=422,42.3 \%)$ stratifying by intentionality status. This subsample did not differ notably from the main ELSA sample on any demographic or anthro- 
Jackson et al.: Predictors of Weight Loss in Obese Older Adults: Findings from the USA and the UK

Table 3. Prevalence of, and multivariable logistic regression models predicting, weight loss ( $\geq 5 \%$ ) among obese people in two older adult cohorts

\begin{tabular}{|c|c|c|c|c|c|c|c|c|}
\hline & \multicolumn{4}{|c|}{ HRS cohort $(n=3,398)$} & \multicolumn{4}{|c|}{ ELSA cohort $(n=998)$} \\
\hline & $\begin{array}{l}\text { prevalence, } \\
\text { No. }(\%)\end{array}$ & OR & $95 \% \mathrm{CI}$ & $\mathrm{p}$ & $\begin{array}{l}\text { prevalence, } \\
\text { No. }(\%)\end{array}$ & OR & $95 \% \mathrm{CI}$ & $\mathrm{p}$ \\
\hline \multicolumn{9}{|l|}{ Age } \\
\hline$<65$ years & 457 (24.9) & 1.00 & - & - & $91(15.6)$ & 1.00 & - & - \\
\hline$\geq 65$ years & $518(33.2)$ & 1.55 & $1.33-1.81$ & $<0.001$ & $75(18.2)$ & 1.08 & $0.76-1.53$ & 0.686 \\
\hline \multicolumn{9}{|l|}{ Sex } \\
\hline Male & $342(24.7)$ & 1.00 & - & - & $16(14.6)$ & 1.00 & - & - \\
\hline Female & $633(31.4)$ & 1.31 & $1.11-1.54$ & 0.001 & $105(18.1)$ & 1.18 & $0.83-1.69$ & 0.359 \\
\hline \multicolumn{9}{|l|}{ Ethnicity } \\
\hline White & $710(28.0)$ & 1.00 & - & - & $163(16.6)$ & 1.00 & - & - \\
\hline Non-white & $265(30.8)$ & 1.07 & $0.89-1.27$ & 0.474 & $3(17.6)$ & 1.16 & $0.33-4.16$ & 0.816 \\
\hline \multicolumn{9}{|l|}{ Marital status } \\
\hline Unmarried & $368(31.3)$ & 1.00 & - & - & $60(21.2)$ & 1.00 & - & - \\
\hline Married & $603(27.2)$ & 0.96 & $0.81-1.13$ & 0.600 & $106(14.8)$ & 0.69 & $0.48-1.00$ & 0.048 \\
\hline \multicolumn{9}{|l|}{ Education } \\
\hline Lower & 645 (30.1) & 1.00 & - & - & 131 (16.9) & 1.00 & - & - \\
\hline Higher & 329 (26.4) & 0.94 & $0.80-1.10$ & 0.443 & $34(15.5)$ & 0.96 & $0.63-1.46$ & 0.847 \\
\hline \multicolumn{9}{|l|}{ BMI } \\
\hline$<35 \mathrm{~kg} / \mathrm{m}^{2}$ & $581(25.5)$ & 1.00 & - & - & 119 (15.8) & 1.00 & - & - \\
\hline$\geq 35 \mathrm{~kg} / \mathrm{m}^{2}$ & 394 (35.3) & 1.60 & $1.37-1.87$ & $<0.001$ & 47 (19.3) & 1.24 & $0.85-1.82$ & 0.260 \\
\hline
\end{tabular}

pometric variable. Due to the reduced sample size, these analyses were likely underpowered to detect significant effects, but inspection of the ORs indicated that the only notable difference between the predictors of intentional and unintentional weight loss was that class II/III obese individuals were less likely than class I obese individuals to experience unintentional weight loss ( $\mathrm{OR}=0.36,95 \% \mathrm{CI}=0.07-1.88, \mathrm{p}=0.225)$ but no less likely (or possibly even more likely) to intentionally lose weight $(\mathrm{OR}=1.14,95 \% \mathrm{CI}=0.55-2.34, \mathrm{p}=0.728)$.

\section{Discussion}

This study examined two general population samples of obese older adults, one in the USA and one in the UK, to investigate the predictors of losing $5 \%$ or more of body weight - the amount often used to define clinically meaningful weight loss and associated with improvements in cardiometabolic risk factors $[10,11]$. Weight loss to this extent was surprisingly frequent, occurring in almost one in five obese Britons and almost one in three obese Americans; the latter consistent with self-report data from NHANES [14]. Weight loss was more frequent among individuals with more severe obesity, women, and those who were older and unmarried.

The higher prevalence of clinically meaningful weight loss in the USA than in the UK sample might be due partly to the higher average weight in the obese HRS participants (97.9 vs. $91.1 \mathrm{~kg}$ ) and the higher proportion with class II/III obesity (33\% in HRS vs. 24\% in ELSA). In support of this, prevalence of weight loss was more similar across the two samples in individuals with BMI $30-35 \mathrm{~kg} / \mathrm{m}^{2}$ (26\% in HRS and $16 \%$ in ELSA) than in those with BMI $\geq 35$ $\mathrm{kg} / \mathrm{m}^{2}$ (35\% in HRS and 19\% in ELSA). However, US-UK differences were still apparent, so there may be cultural differences in attitudes to weight loss. The greater emphasis on weight control in the USA along with a very strong 'diet industry' may result in obese Americans feeling more pressure to lose weight, and having more support to do so, than obese Britons. 
Jackson et al.: Predictors of Weight Loss in Obese Older Adults: Findings from the USA and the UK

Attitudes towards health in older age may also be different. Older Americans are less likely to smoke than older Britons $(10 \%$ vs. $14 \%)[23,24]$ or to drink regularly $(36 \%$ vs. $60 \%)[25$, $26]$, which could reflect a more positive attitude to health promotion. There were also methodological differences between the two cohorts in that weight data were self-reported data in HRS and nurse-measured in ELSA. However, although this may have led to underestimation of weight at both times in HRS, there is no obvious reason to expect the difference to be biased towards an appearance of greater weight loss.

The finding that the likelihood of weight loss was higher among participants who were more obese mirrors results from clinical trials in which higher BMI predicts greater weight loss [15]. This effect might occur because heavier individuals tend to perceive their own weight status more accurately [27], and accurate weight perception in overweight/obese adults is associated with higher prevalence of weight loss attempts [28]. It may also be due to higher treatment rates among those with class II/III obesity. Doctors are significantly more likely to recommend weight loss for individuals with a BMI $\geq 35 \mathrm{~kg} / \mathrm{m}^{2}$ than for those at the lower end of the obese range [29], and initiation of treatment with pharmacological weight loss agents is also positively associated with BMI [30].

The higher rate of clinically meaningful weight loss in women, which was statistically significant after controlling for other variables in HRS, with a similar but non-significant pattern in ELSA, may reflect societal pressure towards thinness [31]. The media's pervasive use of slender female images likely contributes to body dissatisfaction as women compare themselves to, and internalize, the thin ideal [32], and female-focused media also provide greater coverage of nutrition [33]. Body weight is not as strongly emphasized as a key feature of attractiveness in men [34].

Older adults in HRS were more likely to lose weight, consistent with evidence that, while people under 55 years tend to gain weight as time passes, from 55 onwards they are more likely to lose weight [35]. This might be a function of increasing concern about future health [36]; which was not assessed in this study. Alternatively, it may be partly attributable to agerelated underlying illness, though sensitivity analyses in the ELSA cohort found that being older than 65 years was associated with both intentional and unintentional weight loss to a similar extent, suggesting the higher rates are unlikely to be the result of deteriorating health alone. In NHANES 2003-2008, older adults ( $\geq 55$ years) were as likely to want to lose weight as younger adults, but less likely to try to lose weight or to take action to prevent weight gain [13]. The discordant findings of lower prevalence of weight loss attempts and higher prevalence of $\geq 5 \%$ weight loss suggest that some of the weight loss that occurred in the $\geq 65$-yearolds may have been unintentional, but it could also be that older people are just more successful in their attempts to lose weight, perhaps from having been through previous weight loss attempts and knowing better what works for them.

We had expected that human or social capital, in terms of being married or more educated, would confer greater success at losing weight but found no support for this. Quite the contrary, married participants were less likely to lose weight in ELSA, and there was no association with education in either group. Married people may feel less pressure to lose weight because their partner accepts them as they are [37]. Unmarried people, on the other hand, may be more concerned about their weight because the stigma of being overweight is disadvantageous in the courtship market [38].

This study had several limitations. First, there are additional factors that may affect intentional weight loss (e.g., motivation or advice to lose weight) that we did not examine. Second, because weight loss was not a primary focus of either ELSA or HRS, there were no data available on weight loss intention in HRS and only 6-year-old data for less than half of the participants in ELSA. However, other studies showed that the majority of obese individuals want to lose weight and most are actively trying to lose weight [13], so intentionality 
Jackson et al:: Predictors of Weight Loss in Obese Older Adults: Findings from the USA and the UK

can be presumed to be relatively high. The prevalence of weight loss in HRS was also similar to the rate of intentional weight loss $(\geq 5 \%)$ in NHANES [14], and the finding that women and those who were heavier were more likely to lose weight mirrors the higher weight loss intentions in these individuals [13]. Our sensitivity analyses on the data that was available on intentionality in ELSA also suggested that heavier individuals were less likely to be losing weight unintentionally, and potentially more likely to be losing it intentionally. However the limited sample size for these analyses meant power was low, making it difficult to draw any firm conclusions. A third limitation is the definition of the comparison group. Even excluding individuals who gained $\geq 5 \%$ of their body weight left a group that showed considerable weight variability. Establishing a clear definition of weight stability is difficult because weight is always subject to a certain amount of fluctuation.

Overall, the results of this study indicate that a surprisingly high number of obese older adults experience clinically meaningful weight loss; with higher rates in the USA than in the UK. However, demographic data alone do not predict who will lose weight. Other than having a higher BMI, being female was the only consistent predictor of weight loss in both cohorts. However, these results do indicate that data from large cohort studies are potentially a valuable source of information on weight change, and it would be useful if studies were to include robust measures of weight loss intention in future waves of data collection. Concerns over safety have limited clinical weight loss studies in older adults, but the high prevalence of weight loss in this study emphasizes the need for more research in this group.

\section{Acknowledgements}

The Health and Retirement Study is funded by the National Institute on Aging (grant number NIA U01AG009740). The English Longitudinal Study of Ageing is funded by the National Institute on Aging (grants numbers 2R01AG7644-01A1 and 2R01AG017644) and a consortium of UK government departments coordinated by the Office for National Statistics.

This work was funded by the UK Medical Research Council, the UK Economic and Social Research Council, and Cancer Research UK. The funders had no role in study design, data collection and analysis, decision to publish, or preparation of the manuscript.

\section{Disclosure Statement}

The authors declare no conflict of interest in the area.

\section{References}

1 Ogden CL, Carroll MD, Kit BK, Flegal KM: Prevalence of obesity in the United States, 2009-2010. NCHS data brief, no 82. Hyattsville, MD: National Center for Health Statistics, 2012. www.cdc.gov/nchs/data/databriefs/ db82.htm\#citationL (last accessed March 18, 2014).

2 Health Survey for England: Health Survey for England - 2010:Trend tables. 2010. www.ic.nhs.uk/statisticsand-data-collections/health-and-lifestyles-related-surveys/health-survey-for-england/health-survey-forengland-2010-trend-tables (last accessed March 18, 2014).

-3 Must A, Spadano J, Coakley EH, Field AE, Colditz G, Dietz WH: The disease burden associated with overweight and obesity. JAMA 1999;282:1523-1529.

4 World Health Organization. Preventing chronic diseases: a vital investment. 2005. www.who.int/chp/chronic_ disease_report/en/ (last accessed March 18, 2014).

-5 Villareal DT, Apovian CM, Kushner RF, Klein S: Obesity in older adults: technical review and position statement of the American Society for Nutrition and NAASO, The Obesity Society. Am J Clin Nutr 2005;82:923-934.

6 Janssen I, Mark AE: Elevated body mass index and mortality risk in the elderly. Obes Rev 2007;8:41-59.

7 Lainscak M, von Haehling S, Doehner W, Anker SD: The obesity paradox in chronic disease: facts and numbers. J Cachexia Sarcopenia Muscle 2012;3:1-4. 


\begin{tabular}{l|l}
\hline Obes Facts 2014;7:102-110 \\
\hline DOI: $10.1159 / 000362196$ & $\begin{array}{l}\text { C 2014 S. Karger GmbH, Freiburg } \\
\text { www.karger.com/ofa }\end{array}$ \\
\hline
\end{tabular}

Jackson et al.: Predictors of Weight Loss in Obese Older Adults: Findings from the USA and the UK

8 Hainer V, Aldhoon-Hainer I: Obesity paradox does exist. Diabetes Care 2013;36(suppl 2):S276-S281.

9 Felix HC, West DS: Effectiveness of weight loss interventions for obese older adults. Am J Health Promot 2013; 27:191-199.

10 Lavie CJ, Milani RV, Artham SM, Patel D, Ventura HO: The obesity paradox, weight loss, and coronary disease. Am J Med 2009;122:1106-1114.

11 Blackburn G: Effect of degree of weight loss on health benefits. Obes Res 1995;3(suppl 2):211s-S216s.

12 US Food and Drug Administration (FDA): Guidance for the Clinical Evaluation of Weight-Control Drugs. Rockville, MD, 1996.

13 Yaemsiri S, Slining MM, Agarwal SK: Perceived weight status, overweight diagnosis, and weight control among US adults: the NHANES 2003-2008 Study. Int J Obes 2011;35:1063-1070.

14 Nicklas JM, Huskey KW, Davis RB, Wee CC: Successful weight loss among obese U.S. adults. Am J Prevent Med 2012;42:481-485.

15 Teixeira PJ, Going SB, Sardinha LB, Lohman TG: A review of psychosocial pre-treatment predictors of weight control. Obes Rev 2005;6:43-65.

16 Pagoto SL, Schneider KL, Oleski JL, Luciani JM, Bodenlos JS, Whited MC: Male inclusion in randomized controlled trials of lifestyle weight loss interventions. Obesity 2012;20:1234-1239.

17 Shavers-Hornaday VL, Lynch CF, Burmeister LF, Torner JC: Why are African Americans under-represented in medical research studies? Impediments to participation. Ethnic Health 1997;2:31-45.

18 Gross CP, Filardo G, Mayne ST, Krumholz HM: The impact of socioeconomic status and race on trial participation for older women with breast cancer. Cancer 2005;103:483-491.

19 Franz MJ, VanWormer JJ, Crain AL, Boucher JL, Histon T, Caplan W, et al: Weight-loss outcomes: a systematic review and meta-analysis of weight-loss clinical trials with a minimum 1-year follow-up. J Am Diet Assoc 2007; 107:1755-1767.

20 Juster FT, Suzman R: An overview of the Health and Retirement Study. J Hum Resources 1995;30:S7-S56.

21 Marmot M, Banks J, Blundell R, Lessof C, Nazroo J: Health, wealth and lifestyles of the older population in England: The 2002 English Longitudinal Study of Ageing. London, Institute for Fiscal Studies, 2003.

22 Grosvenor M, Bulcavage L, Chlebowski RT: Symptoms potentially influencing weight loss in a cancer population. Correlations with primary site, nutritional status, and chemotherapy administration. Cancer 1989;63: 330-334.

23 Centers for Disease Control and Prevention: Vital signs: Current cigarette smoking among adults aged $\geq 18$ years - United States, 2009. 2010. www.cdc.gov/mmwr/preview $/ \mathrm{mmwrhtml} / \mathrm{mm} 5935 \mathrm{a3}$.htm (last accessed March 18, 2014).

24 Office for National Statistics: Opinions and Lifestyle Survey, Smoking Habits amongst Adults, 2012. 2012. www.ons.gov.uk/ons/rel/ghs/opinions-and-lifestyle-survey/smoking-habits-amongst-adults-2012/rftsmoking-2012.xls (last accessed March 18, 2014).

25 Centers for Disease Control and Prevention: Summary Health Statistics for U.S. Adults: National Health Interview Survey, 2011. 2012. www.cdc.gov/nchs/data/series/sr_10/sr10_256.pdf (last accessed March 18, 2014).

26 Office for National Statistics: Drinking Habits Amongst Adults, 2012. 2013. www.ons.gov.uk/ons/rel/ghs/ opinions-and-lifestyle-survey/drinking-habits-amongst-adults-2012/rft-drinking-2012.xls (last accessed March 18, 2014).

27 Gregory CO, Blanck HM, Gillespie C, Maynard LM, Serdula MK: Health perceptions and demographic characteristics associated with underassessment of body weight. Obesity 2008;16:979-986.

28 Duncan DT, Wolin KY, Scharoun-Lee M, Ding EL, Warner ET, Bennett GG: Does perception equal reality? Weight misperception in relation to weight-related attitudes and behaviors among overweight and obese US adults. Int J Behav Nutr Phys Act 2011;8:20.

-29 Clune A, Fischer JG, Lee JS, Reddy S, Johnson MA, Hausman DB: Prevalence and predictors of recommendations to lose weight in overweight and obese older adults in Georgia senior centers. Prevent Med 2010;51:27-30.

-30 Padwal RS, Damjanovic S, Schulze KM, Lewanczuk RZ, Lau DCW, Sharma AM: Canadian physicians' use of antiobesity drugs and their referral patterns to weight management programs or providers: The SOCCER study. J Obes 2011;2011:1-6.

-31 Garner DM, Garfinkel PE, Schwartz D, Thompson M: Cultural expectations of thinness in women. Psychol Rep 1980;47:483-491.

32 Thompson JK, Stice E: Thin-ideal internalization: mounting evidence for a new risk factor for body-image disturbance and eating pathology. Curr Dir Psychol Sci 2001;10:181-183.

-33 Guillen EO, Barr SI: Nutrition, dieting, and fitness messages in a magazine for adolescent women, 1970-1990. J Adolesc Health 1994;15:464-472.

34 Brown PJ, Konner M: An anthropological perspective on obesity. Ann N Y Acad Sci 2006;499:29-46.

-35 Williamson DF, Kahn HS, Remington PL, Anda RF: The 10-year incidence of overweight and major weight gain in US adults. Arch Intern Med 1990;150:665.

36 Demakakos P, Hacker E, Gjonca E: Perceptions of Ageing. 2006. http://eprints.ucl.ac.uk/177483/ (last accessed March 18, 2014).

37 Sobal J, Nicolopoulos V, Lee J: Attitudes about overweight and dating among secondary school students. Int J Obes 1995;19:376-381.

-38 Sheets V, Ajmere K: Are romantic partners a source of college students' weight concern? Eat Behav 2005;6: $1-9$. 